2021-02-01

\title{
Biomedical Applications of Vibrational Spectroscopy: Oral Cancer Diagnostics
}

\author{
Hugh Byrne \\ Technological University Dublin, hugh.byrne@tudublin.ie \\ Isha Behl \\ Technological University Dublin \\ Genecy Calado \\ Technological University Dublin
}

See next page for additional authors

Follow this and additional works at: https://arrow.tudublin.ie/nanolart

Part of the Biological and Chemical Physics Commons, Diagnosis Commons, Oral Biology and Oral Pathology Commons, and the Other Analytical, Diagnostic and Therapeutic Techniques and Equipment Commons

\section{Recommended Citation}

Byrne, H. J. et al. (2021) Biomedical Applications of Vibrational Spectroscopy: Oral Cancer Diagnostics, Spectrochimica Acta Part A: Molecular and Biomolecular Spectroscopy, 252, 119470 (2021) DOI:10.1016/ j.saa.2021.119470

This Article is brought to you for free and open access by the NanoLab at ARROW@TU Dublin. It has been accepted for inclusion in Articles by an authorized administrator of ARROW@TU Dublin. For more information, please contact arrow.admin@tudublin.ie, aisling.coyne@tudublin.ie,gerard.connolly@tudublin.ie.

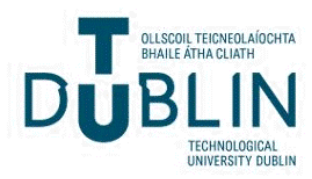




\section{Authors}

Hugh Byrne, Isha Behl, Genecy Calado, Ola Ibrahim, M. Toner, Sheila Galvin, Claire M. Healy, Steven Flint, and Fiona Lyng

This article is available at ARROW@TU Dublin: https://arrow.tudublin.ie/nanolart/106 


\title{
Biomedical Applications of Vibrational Spectroscopy: Oral Cancer Diagnostics
}

Hugh J. Byrne ${ }^{1 *}$, Isha Behl2,3, Genecy Calado ${ }^{2,3}$, Ola Ibrahim4, Mary Toner ${ }^{5}$, Sheila Galvin ${ }^{6}$, Claire M. Healy ${ }^{6}$, Stephen Flint ${ }^{6}$ and Fiona M. Lyng ${ }^{2,3}$

1. FOCAS Research Institute, Technological University Dublin, City Campus, Dublin 8, Ireland

2. School of Physics and Clinical and Optometric Sciences, Technological University Dublin, City Campus, Dublin 8, Ireland

3. Radiation and Environmental Science Centre, FOCAS Research Institute, Technological University Dublin, City Campus, Dublin 8, Ireland

4. School of Dental Science, Trinity College Dublin, Lincoln Place, Dublin 2, Ireland

5. Central Pathology Laboratory, St. James Hospital, James Street, Dublin 8, Ireland

6. Oral Medicine Unit, Dublin Dental University Hospital, Trinity College Dublin, Lincoln Place, Dublin 2, Ireland

* Corresponding Author: Hugh.Byrne@TUDublin.ie

\begin{abstract}
:
Vibrational spectroscopy, based on either infrared absorption or Raman scattering, has attracted increasing attention for biomedical applications. Proof of concept explorations for diagnosis of oral potentially malignant disorders and cancer are reviewed, and recent advances critically appraised. Specific examples of applications of Raman microspectroscopy for analysis of histological, cytological and saliva samples are presented for illustrative purposes, and the future prospects, ultimately for routine, chairside in vivo screening are discussed.
\end{abstract}

\section{Key words:}

Vibrational Spectroscopy, Raman spectroscopy, infrared spectroscopy, Oral cancer, oral pre-cancer. premalignant lesions, potentially malignant lesions disease diagnostics.

\section{Introduction}

Oral cancers are prevalent worldwide, and, in 2018, had estimated age-standardised incidence rate (World) for both sexes, all ages, of 4 per 100,000 population [1]. Critically, carcinoma of the oral cavity has a very poor overall 5 year survival rate of approximately $50 \%$, due mostly to late stage diagnosis [2]. Oral squamous cell carcinoma (OSCC) is the predominant malignancy and is more common in males than females, having a ratio of 1.5:1, and in older persons (aged 50 or over) [3]. Nevertheless, there are currently changes in the trend, manifest as an increase in incidence in young persons, which may be due to HPV infection as opposed to the traditional risk factors such as smoking and tobacco [4].

OSCC arises in the squamous epithelium and, like all cancers, is a multi-step process in which cells acquire mutations that allow them to evade immune surveillance and divide uncontrollably. It can manifest as an endophytic (inward) or exophytic (outward) growth, which can either arise de novo or from oral potentially malignant disorders (OPMD), typically either from a leukoplakia (white plaques of questionable risk having excluded (other) known diseases or disorders that carry no increased risk for cancer), erythroplakia (red patch) or erythroleukoplakia (mixed red and white patch) [5]. Most 
OPMD are symptomless, but some may be associated with bleeding, or soreness. The risk of malignant transformation of these OPMD is determined by a numbers of factors, with the degree of dysplasia being the most significant. The current recommendation for management of OMPDs is that risk factors are addressed and moderate and severely dysplastic oral lesions are excised, while OPMD with no dysplasia is usually followed up annually, mild dysplasia reviewed every 6-12 months

OSCC usually present clinically as a persistent ulcer or hard lump in the oral mucosa, but leukoplakias, erythroplakias and erythroleukoplakias may be found, on biopsy, to harbour OSCC. Patients with advanced OSCC may present with symptoms like difficulty of swallowing or speaking, or swollen lymph nodes in the neck [6]. Following appropriate referral, any suspicious lesion is biopsied and sent for histopathological examination, which is the gold standard for oral cancer diagnosis. After the initial diagnosis of OSCC is made, the cancer staging to determine the tumour size, presence of lymph node or distant metastasis is determined by the use of imaging techniques such as MRI, CT, and PET scans [7]. Cancer stage at diagnosis is the single most important prognostic factor.

Early diagnosis is therefore critical in the management of oral cancer, [8].The low rate of early diagnosis of OSCC can be partially attributed to the late recognition of such OPMDs prior to malignant transformation $[9,10]$. Visual observation of mucosal abnormalities by a dentist or hygienist is the most common starting point of diagnosis, and therefore optical methods play a potential role, currently, and in prospective advances in methodologies for early stage diagnosis [11]. In particular, the vibrational spectroscopic techniques of infrared (IR) absorption and Raman scattering spectroscopies promise the potential for objective, label free, in vivo or ex vivo analysis, which is based on the molecular content of the sample, rather than simply the morphological appearance of abnormalities, a process which can be highly subjective.

This paper describes research efforts towards the development and validation of vibrational spectroscopic methods, typically employing commercially available spectroscopic instrumentation, for the early identification of abnormalities in the oral cavity in tissue, cells and saliva, reviewing literature to date. Specific examples of the application of Raman microspectroscopy, based on work of the authors, are presented. Future perspectives are presented, also in the context of the potential of the technique for in vivo screening and monitoring.

\section{Histopathology}

Both IR and Raman spectroscopies provide a biochemical "fingerprint" of the sample under interrogation, on the basis of the distinctive vibrations of the constituent molecules. They are, however, fundamentally different techniques, as evidenced starkly by the fact that, while Raman spectroscopy is commonly carried out in the visible or near infrared region of the spectrum, IR spectroscopy is commonly carried out in the mid-infrared region. Both can be carried out in the microscopic mode (for further information and comparison of methodologies, see for example [12]), in which, intrinsic limitations to spatial resolution imply that Raman can probe areas of $<1 \mu \mathrm{m}$, whereas IR is typically limited to $\sim 10 \mu \mathrm{m}$. In the field of spectro-histopathology [13], however, the requirement to rapidly scan large areas of tissue probably currently favour the use of IR rather than Raman spectroscopy.

A number of early stage studies demonstrated that Fourier Transform IR (FTIR) microspectroscopy, can be employed to effectively differentiate abnormal and normal states in excised oral tissues, and pointed towards the differences in biochemical composition underpinning the differentiation. Schultz et al. [14] undertook a study which attempted to identify the biochemical differences between well and poorly differentiated oral/oropharyngeal SCC, and demonstrated that spectral features of DNA and keratin can provide the basis for differentiation of clinically classified normal and OSCC biopsies. The prominence of keratin structures in OSCC samples was also explored [15]. Wu et al. [16] demonstrated that normal and malignant oral tissues can be discriminated on the basis of the relative lipid and protein content of fresh oral tissue samples. Comparing tissue from 
normal subgingival sites and OSCC, Fukuyama et al. [17] demonstrated that the spectral characteristics of normal tissue are more strongly influenced by contributions of keratin and collagen, compared to the spectra of abnormal samples. Increasingly sophisticated FTIR spectroscopic imaging methods have provided the capacity to explore different aspects of oral cancer and cancer development. By generating 3D infrared chemical maps, Bruni et al. [18] showed that proliferating and regressive states of head and neck tumours can be identified. A study using FTIR spectroscopy to explore chemopreventive effects of drug-loaded nanoparticles on oral carcinogenesis in animal models has also been reported [19].

Applications of Raman spectroscopy in oral cancer diagnostics began with the analysis of normal and dysplastic tissue in a rat model by Bakker Schut et al. [20], who achieved sensitivity and specificity of $100 \%$ for dysplasia induced in the palate by topical application of the carcinogen 4-nitroquinoline 1oxide. There followed a study of human oral cancer biopsies by Venkatakrishna et al. [21] who obtained an average classification efficiency of $88 \%$. A study carried out by Krishna et al. in 2004 [21] demonstrated the applicability of formalin-fixed oral tissues for optical pathology, revealing significant differences in the epithelial region of normal and malignant samples, arising from the protein composition, conformational/structural changes, and possible increase in protein content in malignant epithelia. In 2006, Malini et al. [22] demonstrated the efficacy of Raman spectroscopic methods in discriminating normal, cancerous, precancerous, and inflammatory conditions. Lipid rich features in normal conditions and prominent protein features in tumours and other pathological conditions were observed. Classification between different groups using multivariate statistical methods produced $100 \%$ sensitivity and specificity [22]. Raman mapping of tissue sections further elucidated biochemical changes within different epithelial layers, which are associated with disease onset [23, 24]. A study by Sunder et al. [25] demonstrated that oral carcinomas of different pathological grades can also be differentiated on the basis of the relative intensities of bands associated with lipids and proteins.

Cals et al. undertook a study of excised tongue tissue samples (11 OCSCC and 14 normal) of 10 patients, to establish multivariate classification models based on Principal Components Analysis (PCA) - Linear Discriminant Analysis (LDA), a binary tumour versus non-tumorous tissue model showing an accuracy of $91 \%$, sensitivity of $100 \%$, and specificity of $78 \%$ [26]. A further study specifically explored samples of OSCC from excised tongue tissue (44 samples from 21 patients) and produced a range of anatomically subclassified spectra, characteristic of OSCC, surface squamous epithelium, muscle, adipose tissue, connective tissue, gland, and nerve [27]. Least squares fitting each characteristic spectrum with combinations of biochemical constituent spectra revealed that the carbohydrates, proteins and amino acids content was the strongest discriminator between OSCC and healthy tissue. Jeng et al. explored the use of Raman microspectroscopy to differentiate excised tumour and normal tissue samples from different anatomical regions; the tongue, the buccal mucosa, and the gingiva of the oral mucosa [28]. Although a high degree of classification was observed for all sites, analysis of the gingiva was seen to yield the highest values of accuracy (91\%), sensitivity (92\%) and specificity (91\%). In addition to protein and amino acid, variations of betacarotene content were identified as a potential biomolecular marker of oral cancer. Jeng et al. compared the performance of the classifier algorithms, PCA - LDA and PCA - quadratic discriminant analysis (QDA), the latter performing better, while Yu et al. applied deep convolutional neural networks to classify squamous cell carcinoma and non-tumorous tissue of the tongue, achieving high values of sensitivity (99.31\%) and specificity (94.44\%) [29].

Although there have been numerous proof-of-concept studies to demonstrate the potential of both IR and Raman spectroscopies for spectro-histopathology, an issue which continues to arise is that of sample presentation [30,31]. Although unadulterated, fresh tissue biopsies are preferable, the goldstandard histopathological method employs a process of formalin fixation followed by paraffin wax embedding. The tissue is first dehydrated and then infiltrated with paraffin wax, such that the samples are stabilised and can be stored for years. These formalin fixed paraffin preserved (FFPP) 
archival tissue libraries can potentially be a vast resource for retrospective studies of patient history and disease progression. Unfortunately, the lipid-like paraffin wax can interfere with either FTIR or Raman spectroscopic analysis [32,33]. A number of different approaches to remove the paraffin wax have been tested. The normal clinical protocols of chemical dewaxing have been demonstrated to be only partially effective [33], and also dependent on the clinical pathology [34], while so called "digital dewaxing" has been shown to be only partially successful [35]. Toward high throughput automated analysis, Pallua et al. [36] demonstrated that high quality FTIR microspectroscopic images can be obtained from formalin-fixed paraffin-embedded tissue microarray sections, providing molecular level information as the basis for diagnosis. However, the symmetrical C-C vibrations of the wax molecule backbone are particularly strong in Raman spectroscopy, and, as the embedded wax is microcrystalline, and the source laser usually polarised, it has been shown that the difficulties in the subtraction of the wax contributions to the Raman spectra of tissue are due to the continuous variability of the spectra [37]. However, by employing a matrix of (300) reference spectra of the wax, Ibrahim et al. demonstrated the effective removal of its contamination, as well as that of the glass substrate (Figure 1), from the spectra of both epithelial and connective tissue of oral biopsies (Figure 2) [37].
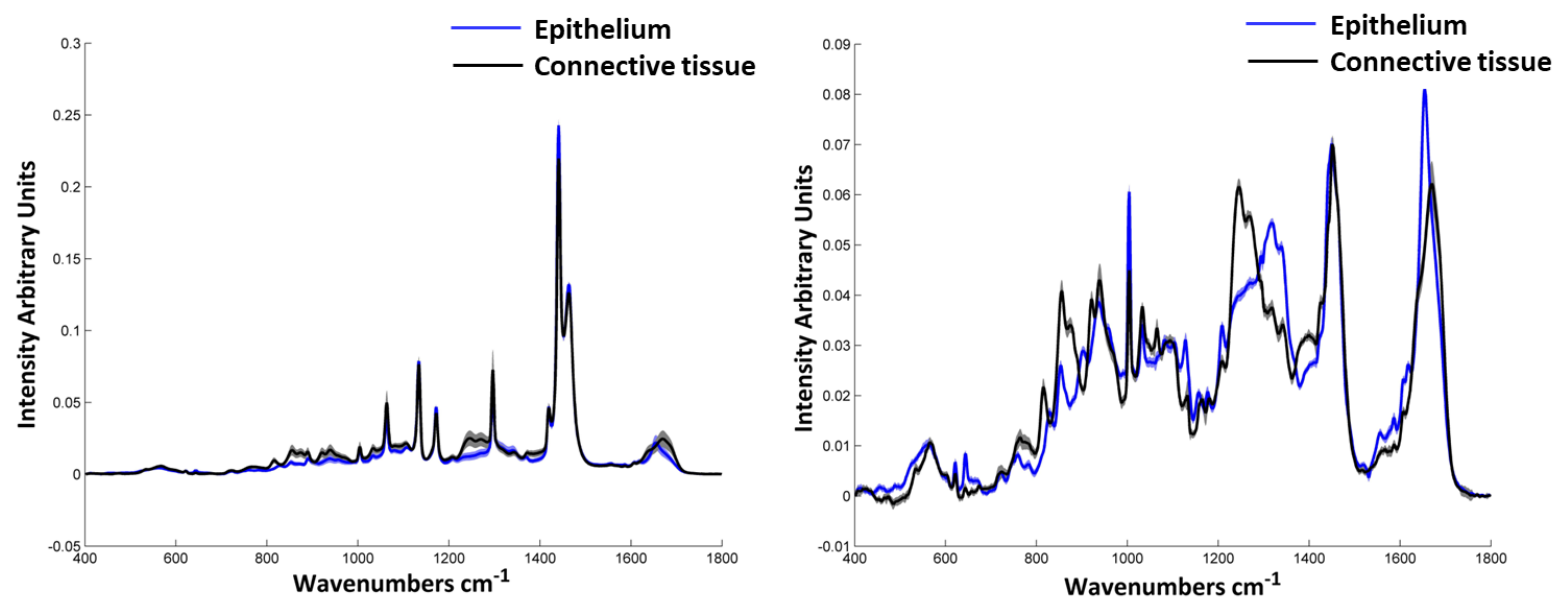

Figure 1: Mean Raman spectra of epithelial and connective tissue before (left) and after (right) digital wax removal. Shading denotes the standard deviation [37].

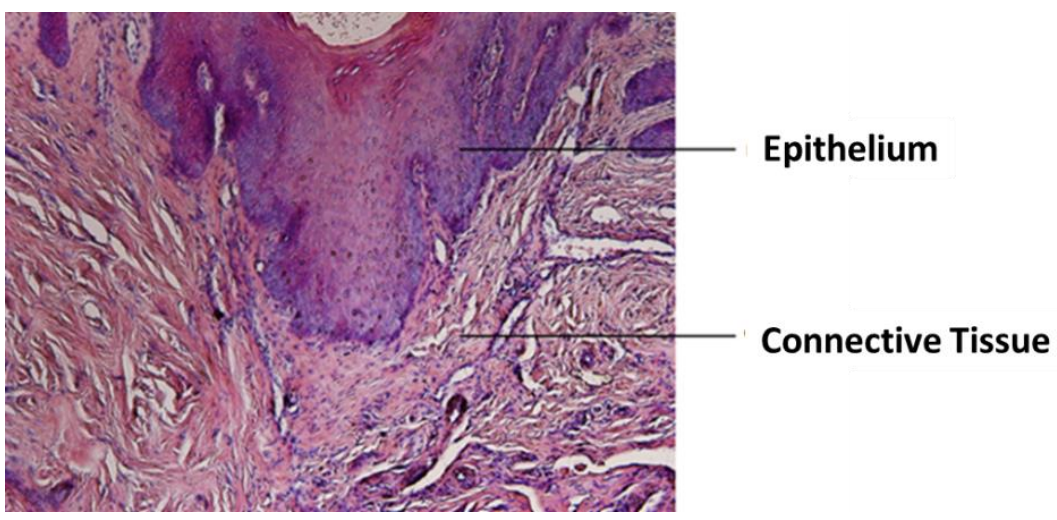

Figure 2: Representative H\&E images showing the regions of epithelium (darkly stained) and connective tissue (lightly stained) [37].

Using the digital processing protocol, Ibrahim explored the potential of vibrational spectroscopy, specifically Raman, to monitor the early stage progression of oral cancer [38]. OSCC is commonly preceded by a range of cell and tissue alterations, termed dysplasia, which indicate an increased risk of malignant transformation. Dysplasia is classified according to severity into mild, moderate, severe/ carcinoma in situ. The initial study therefore undertook to attempt to discriminate 
between mild, moderate and severe dysplasia in FFPP tissues from biopsies of 4 patients who had undergone multiple biopsies over time [38]. Two maps were taken for each pathology, one of epithelium and one of connective tissue. Each consisted of 200 spectral points $(\sim 1 \mu \mathrm{m})$ taken at $10 \mu \mathrm{m}$ intervals. Using a Partial Least Squares, Discriminant Analysis (PLSDA) approach, high degrees of sensitivity and specificity were achieved for classification of each grade of dysplasia, in both tissue regions (Table 1 ).

\begin{tabular}{lcccc}
\hline & \multicolumn{2}{c}{ Epithelium } & \multicolumn{2}{c}{ Connective Tissue } \\
\cline { 2 - 5 } & Sensitivity (\%) & Specificity (\%) & Sensitivity (\%) & Specificity (\%) \\
Severe & 100 & 99 & 98 & 98 \\
Moderate & 96 & 95 & 78 & 84 \\
Mild & 97 & 95 & 91 & 71 \\
\hline
\end{tabular}

Table 1: Sensitivity and specificity values obtained for the PLSDA classification model

Expanding the study to a cohort of 57 patients, the spectroscopic differences between benign, mild, moderate, severely dysplastic and OSCC FFPP tissues were explored [38, 39]. Although the sensitivities and specificities for each grade of dysplasia were in some cases rather low (Table 2), the performance was considerably improved by grouping the mild and moderate groups (Table $3)$, although clinically, mild is considered low risk while moderate and severe dysplasia are considered high risk.

\begin{tabular}{llllll}
\hline & Benign & Mild & Moderate & Severe & OSCC \\
\hline Sensitivity (\%) & 74 & 67 & 39 & 69 & 65 \\
Specificity (\%) & 49 & 38 & 86 & 57 & 76
\end{tabular}

Table 2: Sensitivity and specificity values obtained from PLSDA classification of epithelial tissue.

\begin{tabular}{lllll}
\hline & Benign & Mild/Moderate & Severe & SCC \\
\hline Sensitivity (\%) & 77 & 38 & 74 & 71 \\
Specificity (\%) & 49 & 86 & 52 & 72 \\
\hline
\end{tabular}

Table 3: PLSDA classification of epithelial tissue combining the mild and moderate groups

As the study was based on a heterogeneous group of patients with different gender, age, habits, medical histories and lesion clinical features, the relatively poor performance of the discriminative models prompted an investigation of the potential influence of patient factors and clinical features on Raman classification, such as smoking, alcohol consumption, and anatomical site Tobacco smoke contains carcinogens and has a well established role in the development of both dysplastic [40] and malignant [41] oral lesions. Similarly, alcohol consumption has been associated with the development of both oral dysplasia [40] and cancer [41]. The incidence of 
oral cancer is higher in males than females [42,43], which is likely due to habits such as smoking and alcohol consumption rather than a genetic predisposition, although the prognosis is the same [44]. Gender was not found to have an association with the development of oral dysplastic lesions [40]. Further variability can arise because of the different sites of anatomical origin of the lesion. Oral cancer refers to any cancer in the oral cavity proper which includes; the tongue, labial and buccal mucosa, palate, gingiva, alveolar ridges and floor of the mouth. These areas vary in degree of keratinisation, vascularity and lymphatic drainage [44] and thus anatomic site may also influence the spectroscopic signatures upon which a classification is to be based.

Ibrahim et al. used patient metadata to subdivide the sample spectra, regardless of histopathological diagnosis, into groups according to gender, smoking habits, alcohol consumption and site of lesion [39]. The analysis indicated no discrimination based on gender, or alcohol consumption. Although the lesions came from different anatomical sites in the oral cavity, including the tongue, buccal mucosa, soft palate, hard palate and labial mucosa, the PLSDA classification results were very varied and inclusive, probably due to the low number of samples per site, although grouping according to keratinised (tongue and hard palate) and nonkeratinised (soft palate, buccal and labial mucosa) did show some degree of discrimination. A degree of discrimination was also evident in the epithelia of 3 groups; non-smoker, ex-smokers (previous smokers) and smokers.

Notably, all the pathologies showed the presence of inflammation, increasingly so with increasing severity of dysplasia, consistent with a previous study that has shown increasing inflammatory cell infiltration with increasing severity of oral dysplasia and SCC [45]. PLSDA indicated a high degree of sensitivity and specificity for discrimination of inflamed vs noninflamed for all the pathologies combined, in both epithelial (68\% and $70 \%)$, and connective tissue $(77 \%$ and $86 \%)$. The presence of inflammation in the tumour microenvironment has been well documented $[46,47]$ and is due to multiple factors. The environmental factors that prompt carcinogenesis, such as alcohol and smoking, have been shown to trigger an inflammatory response [48]. Furthermore, the tumour cells release inflammatory mediators which generate an inflammatory microenvironment that promotes cancer growth, invasion and metastasis [49]. A study looking at OSCC surgical margins found that inflamed connective tissue was more likely to misclassify with SCC than non-inflamed connective tissue [50]. The presence of inflammation, particularly in the connective tissue of biopsies, is therefore potentially the most profound factor which may confound the diagnostic accuracy of the technique.

\section{Cytology:}

Oral exfoliative cytology could potentially offer a minimally invasive means of monitoring dysplastic lesions in the oral cavity. Dysplastic and cancerous cells tend to have fewer and weaker connections to each other and to their neighbouring normal cells in the surrounding tissue and thus can easily be collected from the surface of the lesion. Oral brush biopsy is a well-tolerated, minimally invasive and safe method for harvesting cells from the oral cavity but oral cytology has not been widely adopted because of poor sensitivity for identification of dysplasia and cancer [51]. Other techniques, such as DNA analysis and molecular markers, such as melanoma associated antigen A (MAGE-A), lamin-5, Tenascin-C and epidermal growth factor receptor (EGFR), have been shown to improve the sensitivity and specificity of oral cytology [52]. In addition, as oral brush biopsy detects only cellular changes, a surgical biopsy coupled with histopathological assessment must be performed for definitive diagnosis of oral lesions. While cancerous cells can be collected from the surface, this does not constitute a diagnosis, which requires histological proof of breach of basement membrane. Despite this, brush biopsy may be very useful for patients with multiple oral lesions or for monitoring OPMDs 
A limited number of FTIR microspectroscopy studies have been reported, demonstrating the feasibility of diagnosis of oral cancers using single exfoliated cells prepared by cyto-centrifugation onto low e microscope slides [53-57]. Papamarkakis et al. demonstrated that FTIR microspectroscopy could classify oral cells according to anatomical site and that the compositional changes were attributed to the expression of keratins in the cells of the tongue and to the expression of collagen in the cells of the floor of the mouth [54]. In addition, samples from patients with malignancy associated abnormalities were observed to be spectrally similar to a sample from a patient with oral squamous cell carcinoma, and spectrally distinct from samples from healthy volunteers. Spectral differences in oral cells infected with the herpes simplex virus were also reported. Further studies from the same group showed that spectra from exfoliated cells from healthy volunteers could be discriminated from exfoliated cells from patients with oral dysplasia and cancer [55-57].

Similarly, only a limited number of Raman microspectroscopy studies have focussed on oral exfoliated cells. Sahu et al. [58] demonstrated discrimination between patients with oral cancer and healthy volunteers based on increased DNA and differences in protein secondary structure using pellets of oral exfoliated cells and the work was extended to detection of OPMDs [59]. Behl et al. [60] reported a new method for Raman microspectroscopy of single oral exfoliated cells prepared as liquid based cytology samples onto glass slides. A complete methodology incorporating sample collection, sample preparation, spectral acquisition and data pre-processing and analysis was developed (Figure 3).

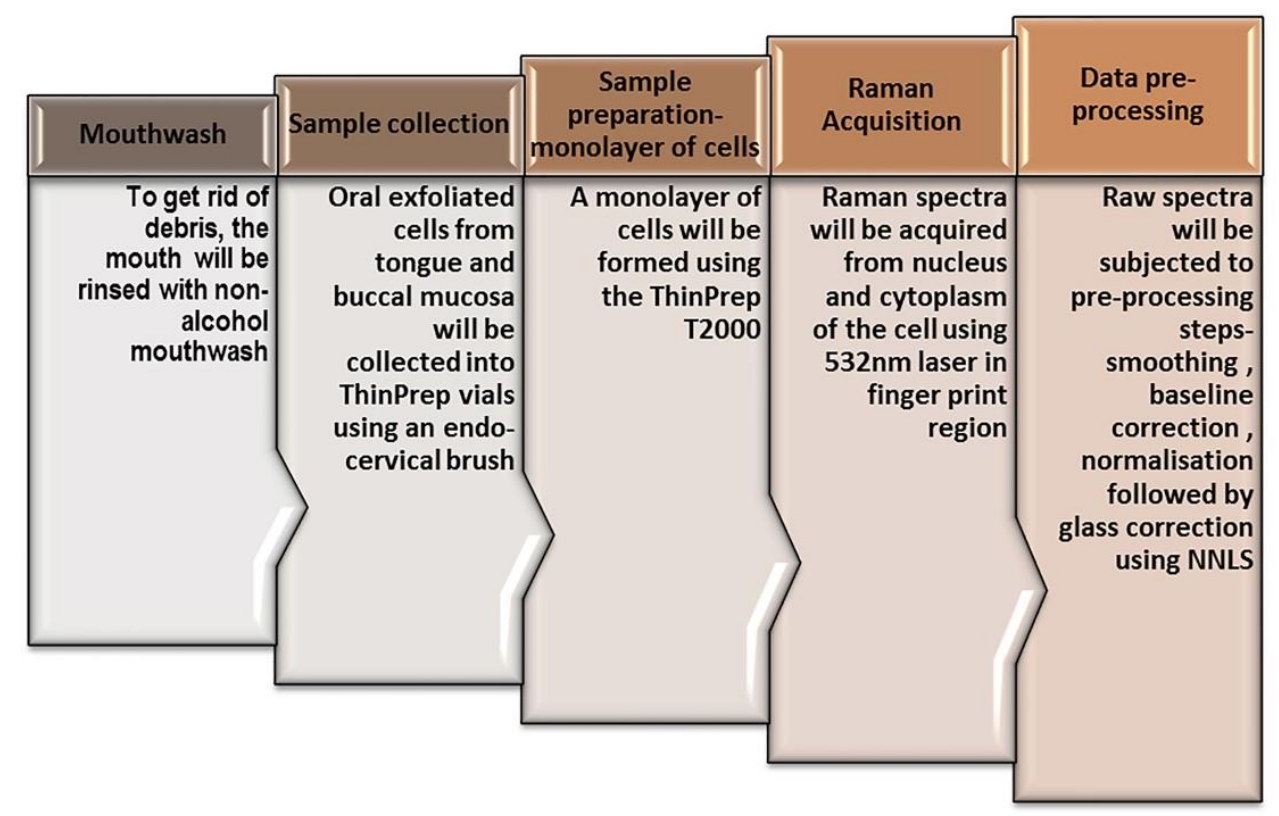

Figure 3: Optimised protocol for the Raman microspectroscopic study of oral exfoliated cells [60].

Further work by Behl et al. [61] analysed brush biopsy cytological samples from healthy donors and from patients with OPMDs, leukoplakia, erythroplakia and erythroleukoplakia, showing mild, moderate or severe dysplasia on histological analysis. Sensitivities of $94 \%$ and $86 \%$ and specificity of $85 \%$ were achieved for discrimination between oral exfoliated cells from healthy donors and from patients with OPMDs, for spectra recorded from the cytoplasm and nucleus respectively, as shown in Figure 4, for the example of cytoplasm. 

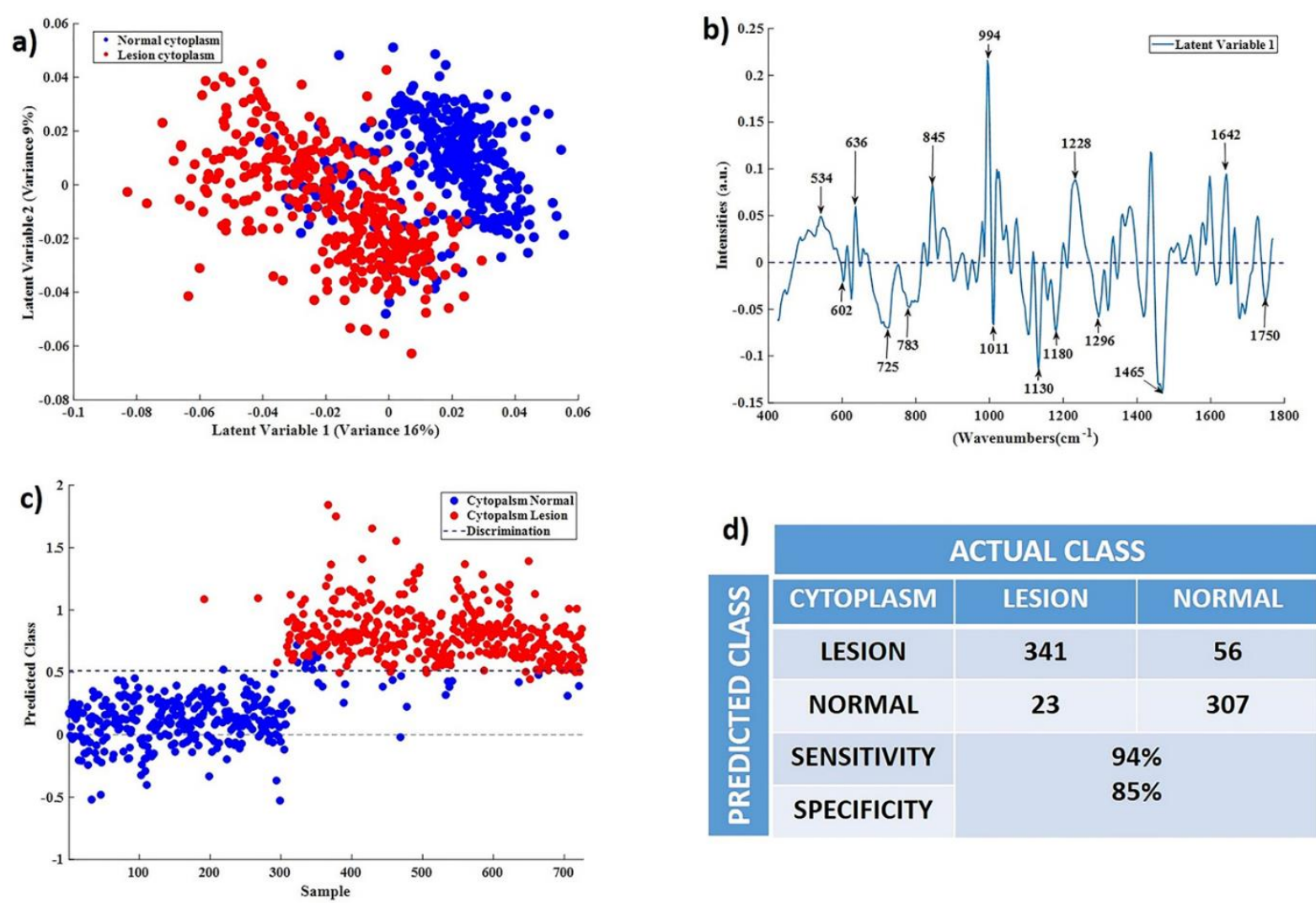

Figure 4: PLS-DA predictive model for cytoplasm (normal vs lesion) a) score plot, b) Latent variable 1, c) predictive model and d) confusion matrix [61].

The discrimination was observed to be mainly based on lipidic contributions from the OPMD samples. This could be attributed to the fact that, during cell division, cells need energy, and this requirement is fulfilled by upregulating the lipid metabolism within the cell. Key spectroscopic features which were seen to be prominent in the PCA differentiation of healthy donors and from patients with OPMDs are identifiable in the Raman spectra of palmitic acid and C14-Ceramide (Figure 5). It is known that, if ceramide synthesis is mediated by a de-novo pathway, it condenses serine and palmitoyl-CoA (betaoxidised form of palmitic acid) as precursors in the endoplasmic reticulum [62]. It was demonstrated that the differentiating PCA loading, in the region $600-1400 \mathrm{~cm}^{-1}$, could be well fitted by a weighted difference of the spectra of palmitic acid and C14-Ceramide. Sphingolipids such as ceramides and sphingosine are building blocks for the eukaryotic plasma membrane. They have an important role to play in intra- or intercellular messengers, signal transduction, inflammation, angiogenesis, metabolic syndrome, neurodegeneration, and cancer/cancer therapy [63]. In mammalian cells, there are $>28$ enzymes for ceramide metabolism and about $>200$ distinct structures. Through this explorative study, although there are many other contributing factors to the differentiating loading which were not fitted, it was successfully demonstrated that ceramides may play an important role in the discrimination of OPMD samples from healthy volunteer samples using Raman microspectroscopy and could therefore act as a spectral marker. Furthermore, this study also indicated that, in OPMDs, ceramide concentration increases in the cell, allowing differentiation of healthy volunteer samples from the OPMD patient samples. 


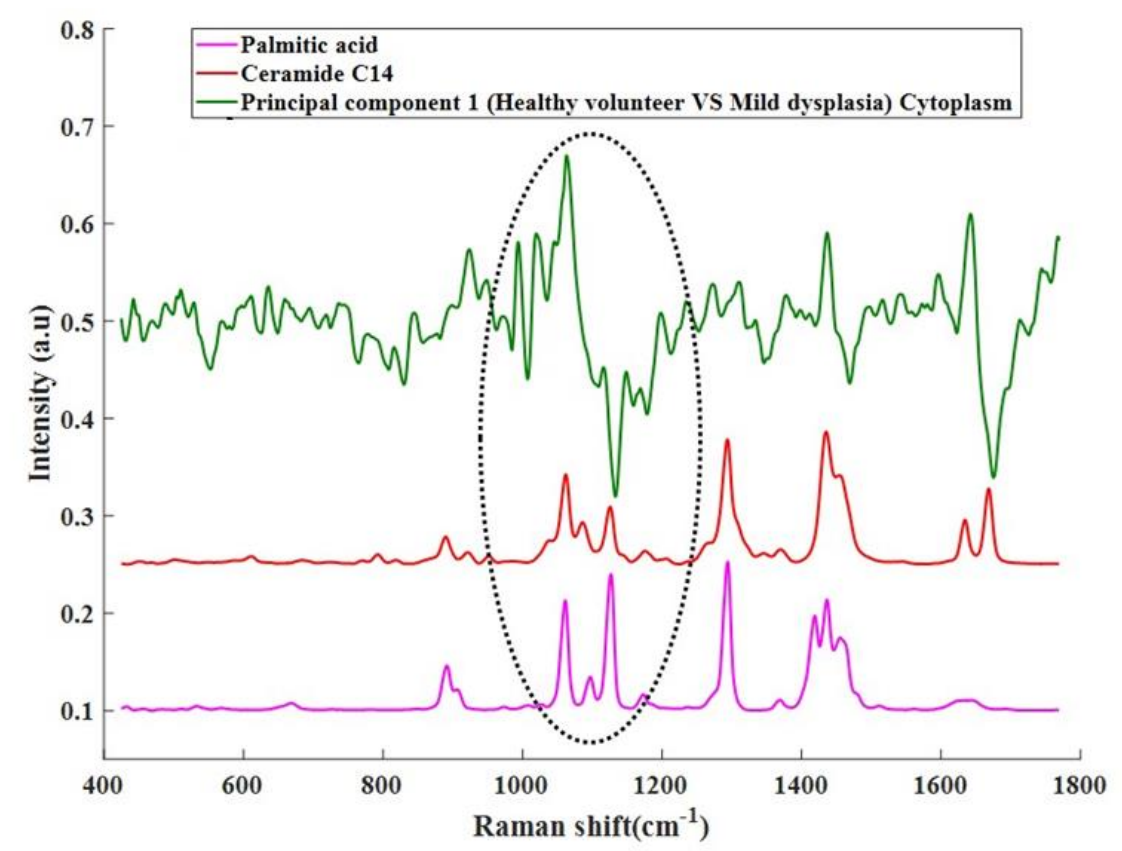

Figure 5: Loading of differentiating principal component for healthy volunteer samples and dysplasia samples indicating bands at 1065 and $1130 \mathrm{~cm}^{-1}$, also observed in the Raman spectra of C14-ceramide and palmitic acid

The study also investigated the influence of age, gender, anatomical site, smoking and alcohol consumption on the classification model. Age, gender, smoking and alcohol consumption were not found to be confounding factors whereas anatomical site was found to influence the classification model. Spectra from gingiva and alveolar mucosa were found to be different to spectra from buccal mucosa and ventral surface of the tongue (Figure 6). As both gingiva and alveolar mucosa are rich in lipids such as ceramides, saturated fatty acids and cholesterol, which act as an antibacterial barrier against infection, cells from these sites showed a similar lipidic spectral profile to cells from OPMDs. Thus, it was concluded that future studies should use separate classification models for buccal mucosa / tongue and for gingiva / alveolar mucosa, and notably, a PLS-DA model based only on buccal mucosa achieved sensitivities and specificities as high as $99 \%$ [61].

a)

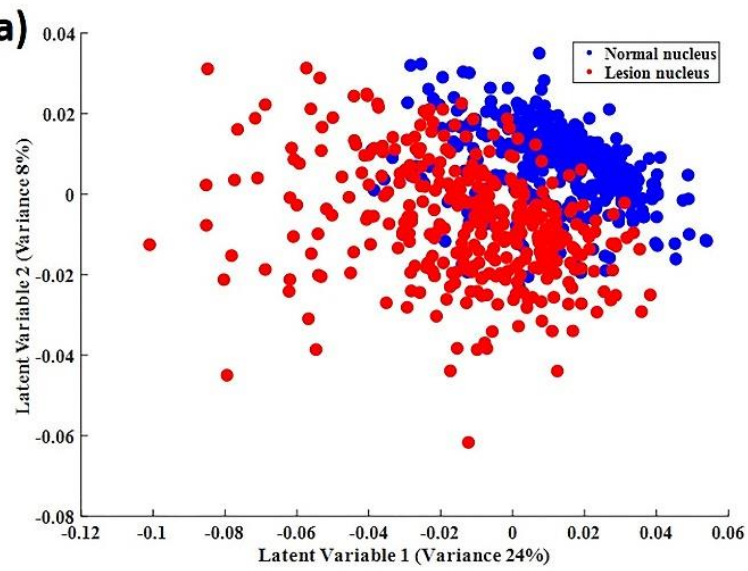

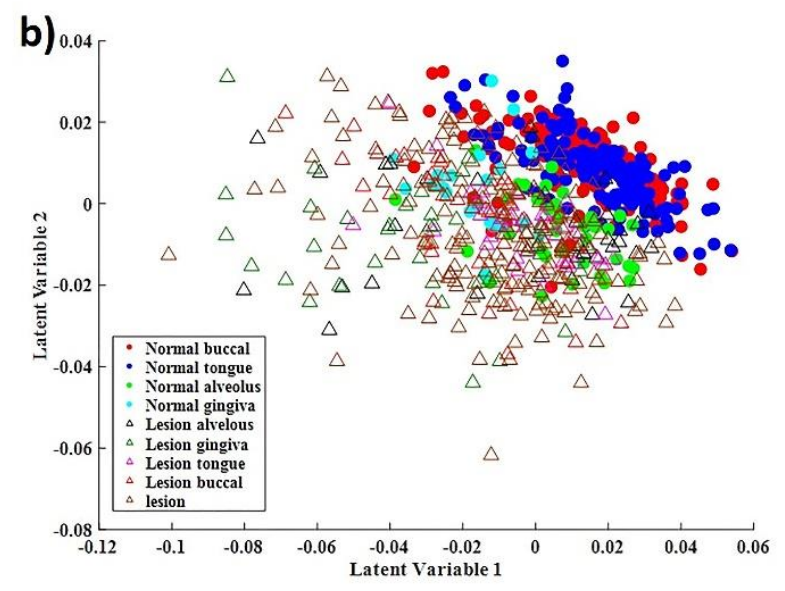

Figure 6: a) PLS-DA score plot for nuclear spectra from healthy donors (normal) vs patients (lesions), b) depicting anatomical sites [61].

Field cancerisation, which can result in multiple OPMDs and in second primary tumours and recurrences, has also been investigated in oral cytology samples $[59,64]$. In the studies of pellets of 
exfoliated cells, Sahu et al. observed an overlap of spectra of cells from contralateral normal sites and spectra from cells from tumour sites in oral cancer patients, indicative of field cancerisation [59]. In the study of Behl et al., oral exfoliated cells were collected from healthy volunteers and from patients with OPMDs, both from the lesion and from contralateral clinically normal mucosa. The study showed that the contralateral normal samples could be classified as spectrally different from the healthy volunteer samples and showed spectral features similar to the lesion samples, particularly in patients who had developed multiple lesions [64]. The effect of smoking, alcohol consumption, degree of dysplasia and gender were explored to understand the factors contributing to the spectral overlap between lesion samples and contralateral normal samples but none of these were found to be confounding factors.

\section{BioFluid analysis:}

As an alternative to histological and/or cytological biopsies, bodily fluids (e.g. plasma, serum, saliva or urine) are emerging as an important source of samples for disease diagnosis and therapeutic monitoring, as their collection is relatively simple, largely non-invasive, and cost effective [65-69] and analysis of biofluids using IR and Raman spectroscopies for diagnostic applications has become increasingly prevalent [70-74]. However, diagnosis based on biofluids does suffer from limitations, such as low analyte concentration, longer acquisition time, and is prone to experimental errors. In the case of FTIR spectroscopy, the relatively strong water absorption means that samples are usually dried before measurement using the Attenuated Total Reflection technique [75], potentially impacting significantly on the clinical workflow [76]. In the case of Raman spectroscopy, signal enhancement using nanoparticles or surface coatings is an active area of research [77]. Nevertheless, it has been demonstrated that quantitative evaluation of high and low molecular weight constituents [78-80], as well as exogenous factors such as viruses [81, 82] and chemotherapeutic agents [83] can be performed on blood serum, in its native aqueous state [84, 85]. Concentration of samples using centrifugal filtration devices has been shown to allow measurement of the analytes in the native aqueous environment [86]. This also allows fractionation according to molecular weight of the constituent analytes, potentially allowing the targeting of molecular biomarkers of a disease.

Raman spectroscopic analysis of blood samples has also been applied to oral cancer diagnostics. It has been demonstrated that serum samples from patients that had been diagnosed with buccal mucosa and tongue cancer can be distinguished from those from healthy volunteers [87]. Amino acids and lipids were the most significant Raman bands identified in the analysis, and an efficacy of $85 \%$ was determined. Raman spectroscopy of serum samples was also able to predict a potential reoccurrence of oral cancer [87].

In a study of urine samples of healthy subjects and oral cancer patients using Raman spectroscopy, it was demonstrated that the technique can provide diagnostic discrimination with an accuracy of $94 \%$ [88]. Voided raw urine was collected from 167 patients and spectroscopic evaluation revealed elevated intensities of features associated with uric acid, specifically C-C stretching at 558 and 649 $\mathrm{cm}^{-1}$ and $\mathrm{N}-\mathrm{H}$ stretching at $798 \mathrm{~cm}^{-1}$, in cancer patients compared to healthy volunteers. Four Raman bands related to creatinine also showed increases, while the band at $692 \mathrm{~cm}^{-1}$ was only present in cancer patients.

Amongst biofluids, saliva has gained increasing interest as a diagnostic fluid, since it represents a non-invasive, safe and cheap source of complex biomolecular information which can easily be obtained from the oral cavity [89]. Whole saliva refers to the complex mixture of fluids from the salivary glands, the gingival crevice, oral mucosa transudate, in addition to mucus of the nasal cavity and pharynx, non-adherent oral bacteria, food debris, desquamated epithelial and blood cells. Saliva is composed of more than $99 \%$ water. Saliva also contains a variety of electrolytes, including sodium, potassium, calcium, magnesium, bicarbonate, and phosphates. Also found in saliva are immunoglobulins, proteins, enzymes, mucins, and nitrogenous products, such as urea and ammonia 
[90]. Recent years have seen the development of salivary diagnostic tools to potentially monitor various oral diseases, ranging from periodontal diseases, dental caries to infections and autoimmune diseases, although saliva may be used not only to potentially detect oral diseases but also systemic ones, showing versatility and merit in diagnostic scope. Salivary biomarkers have already shown promising results in the diagnosis of many diseases, such as periodontitis [91], HIV [92], Hepatitis B [93], and even measles [94]. Immunoassays have been developed to detect secretory IgA and serumderived IgG (from crevicular fluid) found in saliva for various diseases, as well as saliva has shown potential for hormone and drug screening [95].

A systematic review of the literature on vibrational spectroscopic analysis of saliva for diagnostic applications was recently performed by Derruau et al. [96-103]. Of the identified relevant studies, those relating to oral pathologies were exclusively studied by Raman spectroscopy, and a slightly earlier review of the literature reporting analysis of saliva samples for the diagnosis of oral cancer by Calado et al. [104] revealed the literature to be very sparse, and that the majority of studies to date have been carried out using Surface Enhanced Raman scattering techniques [94]. Values of sensitivity, specificity and/or classification efficiency higher than $90 \%$ were demonstrated for the diagnosis of OSCC. Peaks/bands associated with salivary components such as proteins, glycoproteins and lipids were variably identified as potentially associated with the presence of OSCC/oral epithelial dysplasia in all the studies reviewed. A more recent study examined different sampling methodologies, including air-dried, lyophilised, pellet and supernatant sampling, and concluded that the former two forms may be more appropriate for saliva sampling [95]. The method was tested for classification of oral cancer and healthy subjects $(n=27)$, yielding $90 \%$ differentiation efficiency.

Notable in the reviews of Derruau et al. [105] and Calado et al. [105] is the inconsistency of the methodologies employed to date, particularly with regard to the sample collection process. Saliva can be either stimulated (e.g. by mastication) or non-stimulated, and the contribution of each salivary gland to, and therefore the average compositions of, each can vary significantly. Raman analysis of stimulated and non-stimulated saliva from the same donors, however, confirms the significance of the different compositions [105]. In terms of clinical workflow, however, collection times for non stimulated saliva (10-15 minutes) are significantly longer than those for stimulated saliva (2-3 minutes), and so the latter methodology is more favourable for translation to the clinic, and was utilised for a proof-of-concept study exploring Raman spectroscopy for identification of OPMDs and OSCC [105]. In a study of saliva samples of 45 OPMD/OSCC patients and 45 normal volunteer donors, a binary comparison using PLSDA resulted in a sensitivity and specificity of $86 \%$ and $89 \%$, respectively. Efforts to classify the OPMDs vs OSCC groups, and mild/moderate/severe dysplasia subgroups of OPMD, resulted in significantly lower sensitivity/specificity, although it should be noted that, as the patient numbers were rather limited, and even more so when subdivided into grades, the analysis was necessarily performed on very imbalanced data pairs of subsets which can impact the data analysis protocol. However, using a randomised selection process to balance the datasets, sensitivity and specificity of $75 \%$ and $72 \%$ were achieved for classification of the OPMDs vs OSCC groups [106]. The influence of patient factors and potential confounding factors on the Raman spectroscopic classification through saliva analysis was also explored in the same dataset. Partial least squares discriminant analysis did not show any statistical influence of the gender, age profile or alcohol consumption habits of the groups, although it was noticeable that the smoker control and patient groups seemed to exhibit a high degree of misclassification, which could represent a possible confounding factor for the misdiagnosis of smokers as having dysplasia [30].

\section{In Vivo:}

Although IR spectroscopy provides a detailed fingerprint of the biochemical content of a sample, it has predominantly been used for the analysis of human tissues ex vivo. Its application to in vivo diagnosis is limited, because of the short penetration depth and the relatively strong IR absorption of water in both the fingerprint $\left(\sim 1640 \mathrm{~cm}^{-1}\right)$ and high wavenumber $\left(\sim 3200-3300 \mathrm{~cm}^{-1}\right)$ regions of the 
spectrum. Conventional optical fibers have limited transparency in the infrared region, and, although mid-infrared probes have been explored for in vivo applications [107], Raman spectroscopy is generally considered a more favourable option for in vivo applications [108]. Using fiber optic probes, Guze et al. undertook an in vivo Raman spectroscopy study to establish whether the spectroscopic signatures of normal oral mucosa are reproducible across different anatomic sites and subjects of different race and gender [109]. Spectroscopic sampling of the; buccal mucosa, gingiva, dorsal and ventral surfaces of the tongue, floor of the mouth, mucosa of the lower lip, and hard palate, indicated that different sites are differentiated on the basis of degree of keratinisation. Bergholt et al. [110] performed a more detailed characterisation of the in vivo Raman spectroscopic profiles of a similar range of anatomical regions, fitting of the spectra with those of reference biochemical constituents. The study concluded that the histological and morphological characteristics of the different sites have a significant influence on the in vivo Raman profiles, and demonstrated, using partial least squares-discriminant analysis, that the different sites can be classified with an accuracy of $\sim 85 \%$. Sahu et al. [111] demonstrated that in vivo Raman spectroscopy methods can also be utilised to understand age-related changes in the oral mucosa. Singh et al. [112] verified that such in vivo analyses can be performed within clinically feasible timeframes and notably the potential to differentiate normal and pathologically abnormal regions was demonstrated, despite the anatomical variability [113], while a further study explored tobacco-induced cancer field effects in the oral mucosa [114].

Inadequate resection margins in oral cancer surgery increase the likelihood of local recurrence [50]. The use of Raman spectroscopy as an aid in delineation of surgical margins has been explored extensively in recent years [115], and notably it has been shown that OSCC can be discriminated from surrounding normal structures with a high degree of accuracy, although it is more likely to misclassify with surrounding normal and dysplastic epithelium [116]. Water concentration was found to be higher in tumours compared to the surrounding normal tissue, therefore potentially acting as an in vivo guide to surgical resection [117]. An in-vivo study by Malik et al. even found that Raman spectroscopy can predict local recurrence in oral cancers with a sensitivity of $80 \%$ and specificity of $30 \%$ [118].

\section{Discussion and Future Perspectives}

In the various areas of potential clinical application, vibrational spectroscopies have been demonstrated to hold much promise in the identification, diagnosis and treatment of oral cancers, at least at the proof of concept level. In addition to identification of the presence of disease, the techniques can potentially differentiate between high grade (moderate/severe dysplasia) and low grade (no/mild dysplasia) lesions, and between dysplasia and inflammation. It is important to consider, however, the relative merits of the techniques, and the potential for achieving their translation. In all cases, both IR absorption and Raman spectroscopies offer the benefits of being label free, non destructive, and capable of delivering an objective analysis which is based on the biomolecular composition of the sample, which can be manifest at the early stages of the disease development, rather than morphological changes, the assessment of which can be subjective, and manifest only at the later stages of disease progression.

In the case of analysis of tissue biopsies, imaging or mapping of considerably large areas is required, which is time consuming, and computationally intensive. The former consideration probably favours the use of IR absorption techniques. The incorporation of Focal Plane Array detectors in FTIR microscopes enables the simultaneous acquisition of several thousands of spectra [119] and the more recent emergence of tuneable IR quantum cascade laser spectrometer systems potentially offers a further step change in data acquisition and processing speeds, which renders the feasibility of rapid screening of large tissue areas more credible [120]. In comparison, the lower spatial resolution and/or challenge of the relatively low signal to noise of Raman microspectroscopy makes 
it difficult for the technique to rapidly screen large areas. Notably, however, the similarly emerging techniques of Coherent Raman Scattering (CRS) [121] provide enhancement of signals by several orders of magnitude and are capable of rapid 3D mapping of bio-molecules with sub-micron resolution [122]. CRS microscopy can be implemented by recording the coherent anti-Stokes Raman scattering (CARS) or stimulated Raman scattering (SRS) signal, and both modalities have been explored for clinical and biological studies[123], including rapid, in-situ label-free acquisition of H\&E like images based on the ratio of Raman signals at 2930 and $2845 \mathrm{~cm}^{-1}$, reflecting the different lipid and protein contents [124]. The debate on the relative merits of the two techniques for rapid screening of histological samples continues, therefore. An important consideration in the applications of such label free techniques to tissue based diagnostics, however, is the observation of confounding factors of inflammation in the connective tissue, smoking status, and anatomical site.

The higher intrinsic spatial resolution of Raman microspectroscopy makes it more amenable to the less invasive cytological applications, and the methodologies based on exfoliated cells are readily adaptable from cervical cytology, which is well established in clinical screening programmes internationally, with minimal interruption of workflow [125]. The subcellular regions of nucleus and cytoplasm can be interrogated independently, and it has been observed that they afford comparable, high degrees of sensitivity and specificity of diagnosis [86]. Cytological based diagnosis can notoriously lead to false negative results, due to the sparsity of morphologically abnormal cells on the slide, and consequently low sensitivities [126]. Critically, however, in both cervical [76] and oral [86] cytological samples, it has been demonstrated that morphologically normal cells exhibit abnormal Raman spectroscopic signatures which can be associated with early onset of disease, resulting in significantly increased sensitivities compared to morphologically based cytological diagnostic tests. Anatomical site was seen to be the most obvious potential confounding factor, but it was argued that independent multivariate prediction models can be constructed for keratinised and non-keratinised anatomical regions. The ability to detect and identify field cancerisation presents the possibility to predict the recurrence of multiple lesions.

Saliva represents an even less invasive "liquid biopsy" which shows potential for oral cancer diagnostics, and can readily be probed using either IR or Raman spectroscopy. The differences in diagnostic potential of stimulated and non-stimulated saliva samples has to date not fully been explored, and critically the relative influences of systemic or localised oral disease on their biochemical compositions, which could compromise the specificity of the diagnosis, is not yet clear. Within the context of the increasing application of vibrational spectroscopic techniques for diagnostic screening of biofluids, IR has the disadvantage that the requirement of drying can interrupt the clinical workflow [76], although Raman analysis of biofluids also commonly employs a concentration step, for example through centrifugal filtration [86].

In terms of computational aspects, histopathological applications are probably the most demanding. Both IR and Raman mapping can generate large datasets, the recording, preprocessing and analysis of which can take hours [125]. For all applications, however, once a reference database to establish a predictive model has been, comparative screening of an individual sample is relatively rapid, and "chairside" in vitro analysis could potentially be performed in quasi realtime. In the case of either cytological or biofluid based diagnostic applications, a real significant impact would be the ability to implement the screening in vivo, or "chairside", as part of a routine dental or oral hygiene check-up, or post treatment follow up clinics. In terms of initial capital costs, this makes ATR-FTIR a more attractive alternative to that of Raman. Nevertheless, more compact, less expensive, but high specification Raman microscopic systems for cytological applications are becoming increasingly available, and significantly lower cost fiber based options may be a viable 
alternative for biofluid analysis, reducing capital costs to $€ 10-20 \mathrm{k}$, comparable to those of compact ATR-FTIR instruments. Of course, the ability of such systems to provide sufficient sensitivity and specificity would potentially enable routine chairside in vivo screening of oral lesions and the requirement for invasive biopsies could be reduced. This technology could also be used to assist in directing the clinician to the most appropriate biopsy site in the case of extensive oral lesions or for intra-operative assessment of surgical margins.

\section{Acknowledgements}

Aspects of the work referred to or reproduced in this review were funded by Science Foundation Ireland (12/IP/1494), Dublin Institute of Technology Fiosraigh Postgraduate Scholarship Scheme, and Science without Borders (Brazil).

\section{References}

1. Siegel RL, Miller KD, Jemal A (2020) Cancer statistics, 2020. CA: A Cancer Journal for Clinicians 70:7-30 . https://doi.org/10.3322/caac.21590

2. Poh CF, Macaulay CE, Laronde DM, Michele Williams P, Zhang L, Rosin MP (2011) Squamous cell carcinoma and precursor lesions: Diagnosis and screening in a technical era. Periodontology 2000 57:73-88 . https://doi.org/10.1111/j.1600-0757.2011.00386.x

3. Hussein AA, Helder MN, de Visscher JG, Leemans CR, Braakhuis BJ, de Vet HCW, Forouzanfar T (2017) Global incidence of oral and oropharynx cancer in patients younger than 45 years versus older patients: A systematic review. European Journal of Cancer 82:115-127 . https://doi.org/10.1016/j.ejca.2017.05.026

4. Chaturvedi AK, Anderson WF, Lortet-Tieulent J, Paula Curado M, Ferlay J, Franceschi S, Rosenberg PS, Bray F, Gillison ML (2013) Worldwide trends in incidence rates for oral cavity and oropharyngeal cancers. Journal of Clinical Oncology 31:4550-4559 . https://doi.org/10.1200/JCO.2013.50.3870

5. Bánóczy J (1997) Oral cancer and precancerous lesions. Fogorvosi szemle 90 Spec No:27 . https://doi.org/10.3322/canjclin.52.4.195

6. Varela-Centelles P, López-Cedrún JL, Fernández-Sanromán J, Seoane-Romero JM, Santos de Melo N, Álvarez-Nóvoa P, Gómez I, Seoane J (2017) Key points and time intervals for early diagnosis in symptomatic oral cancer: a systematic review. International Journal of Oral and Maxillofacial Surgery 46:1-10 . https://doi.org/10.1016/j.ijom.2016.09.017

7. Genden EM, Ferlito A, Silver CE, Takes RP, Suárez C, Owen RP, Haigentz M, Stoeckli SJ, Shaha AR, Rapidis AD, Rodrigo JP, Rinaldo A (2010) Contemporary management of cancer of the oral cavity. European Archives of Oto-Rhino-Laryngology 267:1001-1017 . https://doi.org/10.1007/s00405-010-1206-2

8. Massano J, Regateiro FS, Januário G, Ferreira A (2006) Oral squamous cell carcinoma: Review of prognostic and predictive factors. Oral Surgery, Oral Medicine, Oral Pathology, Oral Radiology and Endodontology 102:67-76

9. Schneider IJC, Flores ME, Nickel DA, Martins LGT, Traebert J (2014) Sobrevida de pacientes com câncer de lábio, boca e faringe: Um estudo de coorte de 10 anos. Revista Brasileira de Epidemiologia 17:680-691 . https://doi.org/10.1590/1809-4503201400030009 
10. Varela P, Manuel J, Gmez I, Diz-Dios P, de Melo NS, Seoane J (2012) Timing of Oral Cancer Diagnosis: Implications for Prognosis and Survival. In: Oral Cancer. InTech

11. Singh SP, Ibrahim O, Byrne HJ, Mikkonen JW, Koistinen AP, Kullaa AM, Lyng FM (2016) Recent advances in optical diagnosis of oral cancers: Review and future perspectives. Head and Neck 38:E2403-E2411

12. Byrne HJ, Sockalingum GD, Stone N (2011) Raman microscopy: Complement or competitor? In: RSC Analytical Spectroscopy SeriesDevelopment of a high throughput (HT) Raman spectroscopy method for rapid screening of liquid blood plasma from prostate cancer patients

13. Diem M, Mazur A, Lenau K, Schubert J, Bird B, Miljković M, Krafft C, Popp J (2013) Molecular pathology via IR and Raman spectral imaging. Journal of Biophotonics 6:855-886

14. Schultz CP, Liu KZ, Kerr PD, Manisch HH (1998) In situ infrared histopathology of keratinization in human oral/oropharyngeal squamous cell carcinoma. Oncology Research 10:277-286

15. Schultz CP, Mantsch HH (1998) Biochemical imaging and 2D classification of keratin pearl structures in oral squamous cell carcinoma. Cellular and molecular biology (Noisy-le-Grand, France) 44:203-210

16. Wu JG, Xu YZ, Sun CW, Soloway RD, Xu DF, Wu QG, Sun KH, Weng SF, Xu GX (2001) Distinguishing malignant from normal oral tissues using FTIR fiber-optic techniques. Biopolymers - Biospectroscopy Section 62:185-192 . https://doi.org/10.1002/bip.1013

17. Fukuyama Y, Yoshida S, Yanagisawa S, Shimizu M (1999) A study on the differences between oral squamous cell carcinomas and normal oral mucosas measured by Fourier transform infrared spectroscopy. Biospectroscopy 5:117-126 . https://doi.org/10.1002/(SICI)15206343(1999)5:2<117::AID-BSPY5>3.0.CO;2-K

18. Bruni P, Conti C, Giorgini E, Pisani M, Rubini C, Tosi G (2004) Histological and microscopy FTIR imaging study on the proliferative activity and angiogenesis in head and neck tumours. Faraday Discussions 126:19-26 . https://doi.org/10.1039/b306787b

19. Krishnakumar N, Sulfikkarali NK, Manoharan S, Nirmal RM (2013) Screening of chemopreventive effect of naringenin-loaded nanoparticles in DMBA-induced hamster buccal pouch carcinogenesis by FT-IR spectroscopy. Molecular and Cellular Biochemistry 382:27-36 . https://doi.org/10.1007/s11010-013-1715-6

20. Bakker Schut TC, Witjes MJH, Sterenborg HJCM, Speelman OC, Roodenburg JLN, Marple ET, Bruining HA, Puppels GJ (2000) In vivo detection of dysplastic tissue by Raman spectroscopy. Analytical Chemistry 72:6010-6018 . https://doi.org/10.1021/ac000780u

21. Venkatakrishna K, Kurien J, Pai KM, Valiathan M, Kumar NN, Krishna CM, Ullas G, Kartha VB (2001) Optical pathology of oral tissue: A Raman spectroscopy diagnostic method. Current Science 80:665-669

22. Malini R, Venkatakrishna K, Kurien J, Pai KM, Rao L, Kartha VB, Krishna CM (2006) Discrimination of normal, inflammatory, premalignant, and malignant oral tissue: A Raman spectroscopy study. Biopolymers 81:179-193 . https://doi.org/10.1002/bip.20398 
23. Cals FL, Bakker Schut TC, Koljenovic̈ S, Puppels GJ, de Jong RJB (2013) Method development: Raman spectroscopy-based histopathology of oral mucosa. Journal of Raman Spectroscopy 44:963-972 . https://doi.org/10.1002/jrs.4318

24. Behl I, Kukreja L, Deshmukh A, Singh SP, Mamgain H, Hole AR, Krishna CM (2014) Raman mapping of oral buccal mucosa: a spectral histopathology approach. Journal of Biomedical Optics 19:126005 . https://doi.org/10.1117/1.JBO.19.12.126005

25. Sunder NS, Rao N, Kartha V, Ullas G, Kurien J (2009) Laser Raman spectroscopy: A novel diagnostic tool for oral cancer. Journal of Orofacial Sciences 1:40-42

26. Cals FL, Koljenović S, Hardillo JA, Baatenburg de Jong RJ, Bakker Schut TC, Puppels GJ (2016) Development and validation of Raman spectroscopic classification models to discriminate tongue squamous cell carcinoma from non-tumorous tissue. Oral Oncology 60:41-47 . https://doi.org/10.1016/j.oraloncology.2016.06.012

27. Cals FL, Bakker Schut TC, Caspers PJ, Baatenburg De Jong RJ, Koljenović S, Puppels GJ (2018) Raman spectroscopic analysis of the molecular composition of oral cavity squamous cell carcinoma and healthy tongue tissue. Analyst 143:4090-4102 .

https://doi.org/10.1039/c7an02106b

28. Jeng M-J, Sharma M, Sharma L, Chao T-Y, Huang S-F, Chang L-B, Wu S-L, Chow L (2019) Raman Spectroscopy Analysis for Optical Diagnosis of Oral Cancer Detection. Journal of Clinical Medicine 8:1313 . https://doi.org/10.3390/jcm8091313

29. Yu M, Yan H, Xia J, Zhu L, Zhang T, Zhu Z, Lou X, Sun G, Dong M (2019) Deep convolutional neural networks for tongue squamous cell carcinoma classification using Raman spectroscopy. Photodiagnosis and Photodynamic Therapy 26:430-435 . https://doi.org/10.1016/j.pdpdt.2019.05.008

30. Byrne HJ, Baranska M, Puppels GJ, Stone N, Wood B, Gough KM, Lasch P, Heraud P, Sulé-Suso J, Sockalingum GD (2015) Spectropathology for the next generation: Quo vadis? Analyst 140:2066-2073 . https://doi.org/10.1039/c4an02036g

31. Baker MJ, Byrne HJ, Chalmers J, Gardner P, Goodacre R, Henderson A, Kazarian SG, Martin FL, Moger J, Stone N, Sulé-Suso J (2018) Clinical applications of infrared and Raman spectroscopy: State of play and future challenges. Analyst 143:1735-1757 . https://doi.org/10.1039/c7an01871a

32. Baker MJ, Trevisan J, Bassan P, Bhargava R, Butler HJ, Dorling KM, Fielden PR, Fogarty SW, Fullwood NJ, Heys KA, Hughes C, Lasch P, Martin-Hirsch PL, Obinaju B, Sockalingum GD, SuléSuso J, Strong RJ, Walsh MJ, Wood BR, Gardner P, Martin FL (2014) Using Fourier transform IR spectroscopy to analyze biological materials. Nature Protocols 9:1771-1791 . https://doi.org/10.1038/nprot.2014.110

33. Ó Faoláin E, Hunter MB, Byrne JM, Kelehan P, Lambkin HA, Byrne HJ, Lyng FM (2005) Raman spectroscopic evaluation of efficacy of current paraffin wax section dewaxing agents. Journal of Histochemistry and Cytochemistry 53:121-129 . https://doi.org/10.1369/jhc.4A6536.2005

34. Fullwood LM, Griffiths D, Ashton K, Dawson T, Lea RW, Davis C, Bonnier F, Byrne HJ, Baker MJ (2014) Effect of substrate choice and tissue type on tissue preparation for spectral histopathology by Raman microspectroscopy. Analyst 139:446-454 . https://doi.org/10.1039/c3an01832f 
35. Tfayli A, Gobinet C, Vrabie V, Huez R, Manfait M, Piot O (2009) Digital dewaxing of Raman signals: Discrimination between nevi and melanoma spectra obtained from paraffinembedded skin biopsies. Applied Spectroscopy 63:564-570 .

https://doi.org/10.1366/000370209788347048

36. Pallua JD, Pezzei C, Zelger B, Schaefer G, Bittner LK, Huck-Pezzei VA, Schoenbichler SA, Hahn $\mathrm{H}$, Kloss-Brandstaetter A, Kloss F, Bonn GK, Huck CW (2012) Fourier transform infrared imaging analysis in discrimination studies of squamous cell carcinoma. Analyst 137:39653974 . https://doi.org/10.1039/c2an35483g

37. Ibrahim O, Maguire A, Meade ADD, Flint S, Toner M, Byrne HJJ, Lyng FMM (2017) Improved protocols for pre-processing Raman spectra of formalin fixed paraffin preserved tissue sections. Analytical Methods 9:4709-4717 . https://doi.org/10.1039/c6ay03308c

38. Ibrahim O (2017) The Potential of Raman Spectroscopy in the Diagnosis of Premalignant Oral Lesions Premalignant Oral Lesions. Technological University Dublin

39. Ibrahim O., Toner M., Flint S., Byrne H.J. LFM (2020) The potential of Raman spectroscopy in the diagnosis of dysplastic and malignant oral lesions. Cancers (submitted:

40. Jaber MA, Porter SR, Gilthorpe MS, Bedi R, Scully C (1999) Risk factors for oral epithelial dysplasia - The role of smoking and alcohol. Oral Oncology 35:151-156.

https://doi.org/10.1016/S1368-8375(98)00106-7

41. Hashibe M, Brennan P, Benhamou S, Castellsague X, Chen C, Curado MP, Maso LD, Daudt AW, Fabianova E, Wünsch-Filho V, Franceschi S, Hayes RB, Herrero R, Koifman S, la Vecchia C, Lazarus $P$, Levi F, Mates D, Matos E, Menezes A, Muscat J, Eluf-Neto J, Olshan AF, Rudnai P, Schwartz SM, Smith E, Sturgis EM, Szeszenia-Dabrowska N, Talamini R, Wei Q, Winn DM, Zaridze D, Zatonski W, Zhang ZF, Berthiller J, Boffetta P (2007) Alcohol drinking in never users of tobacco, cigarette smoking in never drinkers, and the risk of head and neck cancer: Pooled analysis in the international head and neck cancer epidemiology consortium. Journal of the National Cancer Institute 99:777-789 . https://doi.org/10.1093/jnci/djk179

42. Chaturvedi AK, Anderson WF, Lortet-Tieulent J, Paula Curado M, Ferlay J, Franceschi S, Rosenberg PS, Bray F, Gillison ML (2013) Worldwide trends in incidence rates for oral cavity and oropharyngeal cancers. Journal of Clinical Oncology 31:4550-4559.

https://doi.org/10.1200/JCO.2013.50.3870

43. Torre LA, Bray F, Siegel RL, Ferlay J, Lortet-Tieulent J, Jemal A (2015) Global cancer statistics, 2012. CA: A Cancer Journal for Clinicians 65:87-108 . https://doi.org/10.3322/caac.21262

44. Massano J, Regateiro FS, Januário G, Ferreira A (2006) Oral squamous cell carcinoma: Review of prognostic and predictive factors. Oral Surgery, Oral Medicine, Oral Pathology, Oral Radiology and Endodontology 102:67-76 . https://doi.org/10.1016/j.tripleo.2005.07.038

45. Mashhadiabbas F, Fayazi-Boroujeni M (2017) Correlation of vascularization and inflammation with severity of oral Leukoplakia. Iranian Journal of Pathology 12:225-230 . https://doi.org/10.30699/ijp.2017.25044

46. Negus RPM, Stamp GWH, Hadley J, Balkwill FR (1997) Quantitative assessment of the leukocyte infiltrate in ovarian cancer and its relationship to the expression of $\mathrm{C}-\mathrm{C}$ chemokines. American Journal of Pathology 150:1723-1734 
47. Talmadge JE (2011) Immune cell infiltration of primary and metastatic lesions: Mechanisms and clinical impact. Seminars in Cancer Biology 21:131-138

48. Takahashi H, Ogata H, Nishigaki R, Broide DH, Karin M (2010) Tobacco Smoke Promotes Lung Tumorigenesis by Triggering IKK $\beta$ - and JNK1-Dependent Inflammation. Cancer Cell 17:89-97 . https://doi.org/10.1016/j.ccr.2009.12.008

49. Feller L, Altini M, Lemmer J (2013) Inflammation in the context of oral cancer. Oral Oncology 49:887-892 . https://doi.org/10.1016/j.oraloncology.2013.07.003

50. Cals FL, Bakker Schut TC, Hardillo JA, Baatenburg De Jong RJ, Koljenović S, Puppels GJ (2015) Investigation of the potential of Raman spectroscopy for oral cancer detection in surgical margins. Laboratory Investigation 95:1186-1196 . https://doi.org/10.1038/labinvest.2015.85

51. H. Alsarraf A, Kujan O, Farah CS (2018) The utility of oral brush cytology in the early detection of oral cancer and oral potentially malignant disorders: A systematic review. Journal of Oral Pathology and Medicine 47:104-116 . https://doi.org/10.1111/jop.12660

52. Mehrotra R (2012) The role of cytology in oral lesions: A review of recent improvements. Diagnostic Cytopathology 40:73-83 . https://doi.org/10.1002/dc.21581

53. Diem M, Papamarkakis K, Schubert J, Bird B, Romeo MJ, Miljković M (2009) The infrared spectral signatures of disease: extracting the distinguishing spectral features between normal and diseased states. Applied Spectroscopy 63:307A-318A .

https://doi.org/10.1366/000370209789806894

54. Papamarkakis K, Bird B, Schubert JM, Miljković M, Wein R, Bedrossian K, Laver N, Diem M (2010) Cytopathology by optical methods: Spectral cytopathology of the oral mucosa. Laboratory Investigation 90:589-598 . https://doi.org/10.1038/labinvest.2010.1

55. Diem M, Miljković M, Bird B, Mazur Al, Schubert JM, Townsend D, Laver N, Almond M, Old O (2016) Cancer screening via infrared spectral cytopathology (SCP): Results for the upper respiratory and digestive tracts. Analyst 141:416-428 . https://doi.org/10.1039/c5an01751c

56. Miljković M, Bird B, Lenau K, Mazur Al, Diem M (2013) Spectral cytopathology: New aspects of data collection, manipulation and confounding effects. Analyst 138:3975-3982 .

https://doi.org/10.1039/c3an00185g

57. Diem M, Mazur A, Lenau K, Schubert J, Bird B, Miljković M, Krafft C, Popp J (2013) Molecular pathology via IR and Raman spectral imaging. Journal of Biophotonics 6:855-886. https://doi.org/10.1002/jbio.201300131

58. Sahu A, Tawde S, Pai V, Gera P, Chaturvedi P, Nair S, Krishna CM (2015) Raman spectroscopy and cytopathology of oral exfoliated cells for oral cancer diagnosis. Analytical Methods 7:7548-7559 . https://doi.org/10.1039/c5ay00954e

59. Sahu A, Gera P, Pai V, Dubey A, Tyagi G, Waghmare M, Pagare S, Mahimkar M, Murali Krishna C (2017) Raman exfoliative cytology for oral precancer diagnosis. Journal of Biomedical Optics 22:1 . https://doi.org/10.1117/1.jbo.22.11.115003

60. Behl I, Calado G, Ibrahim O, Malkin A, Flint S, Byrne HJ, Lyng FM (2017) Development of methodology for Raman microspectroscopic analysis of oral exfoliated cells. Analytical Methods 9:937-948. https://doi.org/10.1039/c6ay03360a 
61. Behl I, Calado G, Malkin A, Flint S, Galvin S, Healy CM, Pimentel ML, Byrne HJ, Lyng FM (2020) A pilot study for early detection of oral premalignant diseases using oral cytology and Raman micro-spectroscopy: Assessment of confounding factors. Journal of Biophotonics. https://doi.org/10.1002/jbio.202000079

62. Gault CR, Obeid LM, Hannun YA (2010) An overview of sphingolipid metabolism: From synthesis to breakdown. Advances in Experimental Medicine and Biology 688:1-23 . https://doi.org/10.1007/978-1-4419-6741-1_1

63. Hannun YA, Obeid LM (2011) Many ceramides. Journal of Biological Chemistry 286:2785527862 . https://doi.org/10.1074/jbc.R111.254359

64. Behl I, Calado G, Vishwakarma A, Flint S, Galvin S, Healy CM, Leite Pimentel M, Malkin A, Byrne HJ, Lyng FM (2020) Raman microspectroscopic study for the detection of oral field cancerisation using brush biopsy samples. Journal of Biophotonics 13: .

https://doi.org/10.1002/jbio.202000131

65. Yoshizawa JM, Schafer CA, Schafer JJ, Farrell JJ, Paster BJ, Wong DTW (2013) Salivary biomarkers: Toward future clinical and diagnostic utilities. Clinical Microbiology Reviews 26:781-791 . https://doi.org/10.1128/CMR.00021-13

66. Veenstra TD, Conrads TP, Hood BL, Avellino AM, Ellenbogen RG, Morrison RS (2005) Biomarkers: Mining the biofluid proteome. Molecular and Cellular Proteomics 4:409-418 . https://doi.org/10.1074/mcp.M500006-MCP200

67. Pieper R, Gatlin CL, McGrath AM, Makusky AJ, Mondal M, Seonarain M, Field E, Schatz CR, Estock MA, Ahmed N, Anderson NG, Steiner S (2004) Characterization of the human urinary proteome: A method for high-resolution display of urinary proteins on two-dimensional electrophoresis gels with a yield of nearly 1400 distinct protein spots. Proteomics 4:11591174 . https://doi.org/10.1002/pmic.200300661

68. Pieper R, Gatlin CL, Makusky AJ, Russo PS, Schatz CR, Miller SS, Su Q, McGrath AM, Estock MA, Parmar PP, Zhao M, Huang ST, Zhou J, Wang F, Esquer-Blasco R, Anderson NL, Taylor J, Steiner $S$ (2003) The human serum proteome: Display of nearly 3700 chromatographically separated protein spots on two-dimensional electrophoresis gels and identification of 325 distinct proteins. Proteomics 3:1345-1364 . https://doi.org/10.1002/pmic.200300449

69. Hu S, Loo JA, Wong DT (2006) Human body fluid proteome analysis. Proteomics 6:6326-6353 . https://doi.org/10.1002/pmic.200600284

70. Baker MJ, Hussain SR, Lovergne L, Untereiner V, Hughes C, Lukaszewski RA, Thiéfin G, Sockalingum GD (2016) Developing and understanding biofluid vibrational spectroscopy: A critical review. Chemical Society Reviews 45:1803-1818 . https://doi.org/10.1039/c5cs00585j

71. Goodacre R, Baker MJ, Graham D, Schultz ZD, Diem M, Marques MP, Cinque G, Vernooij R, Sulé-Suso J, Byrne HJ, Faulds K, Hermes M, Fleming H, Bonifacio A, Dluhy R, Gardner P, ElMashtoly S, Wood B, Gough K, Fornasaro S, Kazarian S, Jamieson L, Petrich W, Sockalingum GD, Stone N, Kendall C, Sinjab F, Haris P, Subaihi A, Remiszewski S, Hellwig P, Sergo V, Gerwert K, Phillips C, Campbell CJ (2016) Biofluids and other techniques: general discussion. Faraday Discussions 187:575-601 . https://doi.org/10.1039/C6FD90014C 
72. Leal LB, Nogueira MS, Canevari RA, Carvalho LFCS (2018) Vibration spectroscopy and body biofluids: Literature review for clinical applications. Photodiagnosis and Photodynamic Therapy 24:237-244 . https://doi.org/10.1016/j.pdpdt.2018.09.008

73. Mitchell AL, Gajjar KB, Theophilou G, Martin FL, Martin-Hirsch PL (2014) Vibrational spectroscopy of biofluids for disease screening or diagnosis: Translation from the laboratory to a clinical setting. Journal of Biophotonics 7:153-165.

https://doi.org/10.1002/jbio.201400018

74. Bunaciu AA, Fleschin Ş, Hoang VD, Aboul-Enein HY (2017) Vibrational Spectroscopy in Body Fluids Analysis. Critical Reviews in Analytical Chemistry 47:67-75 . https://doi.org/10.1080/10408347.2016.1209104

75. Butler HJ, Brennan PM, Cameron JM, Finlayson D, Hegarty MG, Jenkinson MD, Palmer DS, Smith BR, Baker MJ (2019) Development of high-throughput ATR-FTIR technology for rapid triage of brain cancer. Nature Communications 10:1-9 . https://doi.org/10.1038/s41467-01912527-5

76. Cameron JM, Butler HJ, Palmer DS, Baker MJ (2018) Biofluid spectroscopic disease diagnostics: A review on the processes and spectral impact of drying. Journal of Biophotonics 11:1-12 . https://doi.org/10.1002/jbio.201700299

77. El-Sayed IH, Huang X, El-Sayed MA (2005) Surface plasmon resonance scattering and absorption of anti-EGFR antibody conjugated gold nanoparticles in cancer diagnostics: Applications in oral cancer. Nano Letters 5:829-834 . https://doi.org/10.1021/nl050074e

78. Parachalil DR, Brankin B, McIntyre J, Byrne HJ (2018) Raman spectroscopic analysis of high molecular weight proteins in solution-considerations for sample analysis and data preprocessing. Analyst 143:5987-5998 . https://doi.org/10.1039/c8an01701h

79. Parachalil DR, Bruno C, Bonnier F, Blasco H, Chourpa I, Mclntyre J, Byrne HJ (2019) Raman spectroscopic screening of high and low molecular weight fractions of human serum. Analyst 144:4295-4311 . https://doi.org/10.1039/c9an00599d

80. Parachalil DR, Bruno C, Bonnier F, Blasco H, Chourpa I, Baker MJ, McIntyre J, Byrne HJ (2019) Analysis of bodily fluids using vibrational spectroscopy: A direct comparison of Raman scattering and infrared absorption techniques for the case of glucose in blood serum. Analyst 144:3334-3346. https://doi.org/10.1039/c9an00125e

81. Mahmood T, Nawaz H, Ditta A, Majeed MI, Hanif MA, Rashid N, Bhatti HN, Nargis HF, Saleem $\mathrm{M}$, Bonnier F, Byrne HJ (2018) Raman spectral analysis for rapid screening of dengue infection. 200:136-142 . https://doi.org/10.1016/j.saa.2018.04.018

82. Nawaz H, Rashid N, Saleem M, Asif Hanif M, Irfan Majeed M, Amin I, Iqbal M, Rahman M, Ibrahim O, Baig SM, Ahmed M, Bonnierg F, Byrnee HJ (2017) Prediction of viral loads for diagnosis of hepatitis $C$ infection in human plasma samples using raman spectroscopy coupled with partial least squares regression analysis. Journal of Raman Spectroscopy 48:697-704 . https://doi.org/10.1002/jrs.5108

83. Parachalil DR, Commerford D, Bonnier F, Chourpa I, Mclntyre J, Byrne HJ (2019) Raman spectroscopy as a potential tool for label free therapeutic drug monitoring in human serum: The case of busulfan and methotrexate. Analyst 144:5207-5214 . https://doi.org/10.1039/c9an00801b 
84. Parachalil DR, Mclntyre J, Byrne HJ (2020) Potential of Raman spectroscopy for the analysis of plasma/serum in the liquid state: recent advances. Analytical and Bioanalytical Chemistry 412:1993-2007 . https://doi.org/10.1007/s00216-019-02349-1

85. Byrne HJ, Bonnier F, McIntyre J, Parachalil DR (2020) Quantitative analysis of human blood serum using vibrational spectroscopy. Clinical Spectroscopy 2:100004 . https://doi.org/10.1016/j.clispe.2020.100004

86. Bonnier F, Petitjean F, Baker MJ, Byrne HJ (2014) Improved protocols for vibrational spectroscopic analysis of body fluids. Journal of Biophotonics 7:167-179 .

https://doi.org/10.1002/jbio.201300130

87. Sahu A, Sawant S, Mamgain H, Krishna CM (2013) Raman spectroscopy of serum: An exploratory study for detection of oral cancers. The Analyst 138:4161 . https://doi.org/10.1039/c3an00308f

88. Elumalai B, Prakasarao A, Ganesan B, Dornadula K, Ganesan S (2014) Raman spectroscopic characterization of urine of normal and oral cancer subjects. Journal of Raman Spectroscopy 46:84-93 . https://doi.org/10.1002/jrs.4601

89. Miller CS, King CP, Langub MC, Kryscio RJ, Thomas M v. (2006) Salivary biomarkers of existing periodontal disease: A cross-sectional study. Journal of the American Dental Association 137:322-329 . https://doi.org/10.14219/jada.archive.2006.0181

90. Ndembi N, Ngansop C, Moudourou S, Tagny CT, Abimiku A, Mbanya DS, Kaptue LN (2011) Can oral fluid testing be used to replace blood-based HIV rapid testing to scale up access to diagnosis and treatment in cameroon? Journal of Acquired Immune Deficiency Syndromes 56: . https://doi.org/10.1097/QAl.0b013e31820a9d1d

91. Fisker N, Georgsen J, Stolborg T, Khalil MR, Christensen PB (2002) Low hepatitis B prevalence among pre-school children in Denmark: Saliva anti-HBc screening in day care centres. Journal of Medical Virology 68:500-504 . https://doi.org/10.1002/jmv.10242

92. Nigatu W, Jin L, Cohen BJ, Nokes DJ, Etana M, Cutts FT, Brown DWG (2001) Measles virus strains circulating in Ethiopia in 1998-1999: Molecular characterisation using oral fluid samples and identification of a new genotype. Journal of Medical Virology 65:373-380. https://doi.org/10.1002/jmv.2044

93. Cone EJ, Presley L, Lehrer M, Seiter W, Smith M, Kardos KW, Fritch D, Salamone S, Niedbala RS (2002) Oral fluid testing for drugs of abuse: Positive prevalence rates by intercept ${ }^{\mathrm{TM}}$ immunoassay screening and GC-MS-MS confirmation and suggested cutoff concentrations. Journal of Analytical Toxicology 26:541-546 . https://doi.org/10.1093/jat/26.8.541

94. Derruau S, Robinet J, Untereiner V, Piot O, Sockalingum GD, Lorimier S (2020) Vibrational spectroscopy saliva profiling as biometric tool for disease diagnostics: A systematic literature. Molecules 25:4142 . https://doi.org/10.3390/molecules25184142

95. Calado G, Behl I, Daniel A, Byrne HJ, Lyng FM (2019) Raman spectroscopic analysis of saliva for the diagnosis of oral cancer: A systematic review. Translational Biophotonics 1: . https://doi.org/10.1002/tbio.201900001 
96. Kho KW, Malini O, Shen ZX, Soo KC (2005) Surface enhanced Raman spectroscopic (SERS) study of saliva in the early detection of oral cancer. In: Priezzhev A v., Cote GL (eds) Optical Diagnostics and Sensing V. SPIE, p 84

97. Feng S, Lin D, Lin J, Huang Z, Chen G, Li Y, Huang S, Zhao J, Chen R, Zeng H (2014) Saliva analysis combining membrane protein purification with surface-enhanced Raman spectroscopy for nasopharyngeal cancer detection. Applied Physics Letters 104:073702 . https://doi.org/10.1063/1.4866027

98. Feng S, Chen R, Lin J, Pan J, Chen G, Li Y, Cheng M, Huang Z, Chen J, Zeng Haishan H (2010) Nasopharyngeal cancer detection based on blood plasma surface-enhanced Raman spectroscopy and multivariate analysis. Biosensors and Bioelectronics 25:2414-2419 . https://doi.org/10.1016/j.bios.2010.03.033

99. Rekha P, Aruna P, Brindha E, Koteeswaran D, Baludavid M, Ganesan S (2016) Near-infrared Raman spectroscopic characterization of salivary metabolites in the discrimination of normal from oral premalignant and malignant conditions. Journal of Raman Spectroscopy 47:763772 . https://doi.org/10.1002/jrs.4897

100. Qiu S, Xu Y, Huang L, Zheng W, Huang C, Huang S, Lin J, Lin D, Feng S, Chen R, Pan J (2016) Non-invasive detection of nasopharyngeal carcinoma using saliva surface-enhanced Raman spectroscopy. Oncology Letters 11:884-890 . https://doi.org/10.3892/ol.2015.3969

101. Connolly JM, Davies K, Kazakeviciute A, Wheatley AM, Dockery P, Keogh I, Olivo M (2016) Non-invasive and label-free detection of oral squamous cell carcinoma using saliva surfaceenhanced Raman spectroscopy and multivariate analysis. Nanomedicine: Nanotechnology, Biology, and Medicine 12:1593-1601 . https://doi.org/10.1016/j.nano.2016.02.021

102. Meenapriya P (2016) Raman Spectroscopic Analysis of Blood, Urine, Saliva and Tissue of Oral Potentially Malignant Disorders and Malignancy-A Diagnostic Study. International Journal of Oral and Craniofacial Science 2:011-014 . https://doi.org/10.17352/2455-4634.000013

103. Qian K, Wang Y, Hua L, Chen A, Zhang Y (2018) New method of lung cancer detection by saliva test using surface-enhanced Raman spectroscopy. Thoracic Cancer 9:1556-1561 . https://doi.org/10.1111/1759-7714.12837

104. Hole A, Tyagi G, Deshmukh A, Deshpande R, Gota V, Chaturvedi P, Krishna CM (2020) EXPRESS: Salivary Raman Spectroscopy: Standardization of Sampling Protocols and Stratification of Healthy and Oral Cancer Subjects. Applied Spectroscopy 000370282097326. https://doi.org/10.1177/0003702820973260

105. Calado G (2020) Development of Methodologies for Raman Spectral Development of Methodologies for Raman Spectral Analysis of Human Saliva for Detection of Oral Analysis of Human Saliva for Detection of Oral Cancer. PhD Thesis, Technological University Dublin

106. Heise HM, Küpper L, Butvina LN (2002) Bio-analytical applications of mid-infrared spectroscopy using silver halide fiber-optic probes. Spectrochimica Acta - Part B Atomic Spectroscopy 57:1649-1663 . https://doi.org/10.1016/S0584-8547(02)00103-9

107. Guze K, Short M, Sonis S, Karimbux N, Chan J, Zeng H (2009) Parameters defining the potential applicability of Raman spectroscopy as a diagnostic tool for oral disease. Journal of Biomedical Optics 14:014016 . https://doi.org/10.1117/1.3076195 
108. Bergholt MS, Zheng W, Huang Z (2012) Characterizing variability in in vivo Raman spectroscopic properties of different anatomical sites of normal tissue in the oral cavity. Journal of Raman Spectroscopy 43:255-262 . https://doi.org/10.1002/jrs.3026

109. Sahu A, Deshmukh A, Ghanate AD, Singh SP, Chaturvedi P, Murali Krishna C (2012) Raman spectroscopy of oral buccal mucosa: A study on age-related physiological changes and tobacco-related pathological changes. Technology in Cancer Research and Treatment 11:529541 . https://doi.org/10.7785/tcrt.2012.500304

110. Singh SP, Deshmukh A, Chaturvedi P, Murali Krishna C (2012) In vivo Raman spectroscopic identification of premalignant lesions in oral buccal mucosa. Journal of Biomedical Optics 17:1050021 . https://doi.org/10.1117/1.jbo.17.10.105002

111. Krishna H, Majumder SK, Chaturvedi P, Gupta PK (2013) Anatomical variability of in vivo Raman spectra of normal oral cavity and its effect on oral tissue classification. Biomedical Spectroscopy and Imaging 2:199-217 . https://doi.org/10.3233/BSI-130042

112. Singh SP, Sahu A, Deshmukh A, Chaturvedi P, Krishna CM (2013) In vivo Raman spectroscopy of oral buccal mucosa: A study on malignancy associated changes (MAC)/cancer field effects (CFE). Analyst 138:4175-4182 . https://doi.org/10.1039/c3an36761d

113. Smits RWH, Koljenovic S, Hardillo JA, ten Hove I, Meeuwis CA, Sewnaik A, Dronkers EAC, Bakker Schut TC, Langeveld TPM, Molenaar J, Hegt VN, Puppels GJ, Baatenburg De Jong RJ (2016) Resection margins in oral cancer surgery: Room for improvement. Head and Neck 38:E2197-E2203 . https://doi.org/10.1002/hed.24075

114. Jermyn M, Desroches J, Aubertin K, St-Arnaud K, Madore WJ, de Montigny E, Guiot MC, Trudel D, Wilson BC, Petrecca K, Leblond F (2016) A review of Raman spectroscopy advances with an emphasis on clinical translation challenges in oncology. Physics in Medicine and Biology 61:R370-R400

115. Barroso EM, Smits RWH, van Lanschot CGF, Caspers PJ, ten Hove I, Mast $H$, Sewnaik A, Hardillo JA, Meeuwis CA, Verdijk R, Hegt VN, Baatenburg De Jong RJ, Wolvius EB, Bakker Schut TC, Koljenović S, Puppels GJ (2016) Water concentration analysis by Raman spectroscopy to determine the location of the tumor border in oral cancer surgery. Cancer Research 76:5945-5953 . https://doi.org/10.1158/0008-5472.CAN-16-1227

116. Malik A, Sahu A, Singh SP, Deshmukh A, Chaturvedi P, Nair D, Nair S, Murali Krishna C (2017) In vivo Raman spectroscopy-assisted early identification of potential second primary/recurrences in oral cancers: An exploratory study. Head and Neck 39:2216-2223 . https://doi.org/10.1002/hed.24884

117. Bassan P, Sachdeva A, Shanks JH, Brown MD, Clarke NW, Gardner P (2014) Automated highthroughput assessment of prostate biopsy tissue using infrared spectroscopic chemical imaging. In: Gurcan MN, Madabhushi A (eds) Medical Imaging 2014: Digital Pathology. SPIE, $p$ 90410D

118. Kimber JA, Kazarian SG (2017) Spectroscopic imaging of biomaterials and biological systems with FTIR microscopy or with quantum cascade lasers. Analytical and Bioanalytical Chemistry 409:5813-5820 . https://doi.org/10.1007/s00216-017-0574-5 
119. Maker PD, Terhune RW (1965) Study of optical effects due to an induced polarization third order in the electric field strength. Physical Review 137:A801 .

https://doi.org/10.1103/PhysRev.137.A801

120. Zumbusch A, Holtom GR, Xie XS (1999) Three-dimensional vibrational imaging by coherent anti-stokes raman scattering. Physical Review Letters 82:4142-4145 .

https://doi.org/10.1103/PhysRevLett.82.4142

121. Schie IW, Krafft C, Popp J (2015) Applications of coherent Raman scattering microscopies to clinical and biological studies. Analyst 140:3897-3909 . https://doi.org/10.1039/c5an00178a

122. Ji M, Orringer DA, Freudiger CW, Ramkissoon S, Liu X, Lau D, Golby AJ, Norton I, Hayashi M, Agar NYR, Young GS, Spino C, Santagata S, Camelo-Piragua S, Ligon KL, Sagher O, Sunney Xie X (2013) Rapid, label-free detection of brain tumors with stimulated raman scattering microscopy. Science Translational Medicine 5:201ra119-201ra119.

https://doi.org/10.1126/scitrans/med.3005954

123. Lyng FM, Traynor D, Ramos IRM, Bonnier F, Byrne HJ, Ramos RM, Bonnier F, Byrne J, Ramos IRM, Bonnier F, Byrne HJ (2015) Raman spectroscopy for screening and diagnosis of cervical cancer. Analytical and Bioanalytical Chemistry 407:8279-8289 .

https://doi.org/10.1007/s00216-015-8946-1

124. Scully C, Bagan J v., Hopper C, Epstein JB (2008) Oral cancer: Current and future diagnostic techniques. American Journal of Dentistry 21:199-209

125. Mayrand M-H, Duarte-Franco E, Rodrigues I, Walter SD, Hanley J, Ferenczy A, Ratnam S, Coutlée F, Franco EL (2007) Human Papillomavirus DNA versus Papanicolaou Screening Tests for Cervical Cancer. New England Journal of Medicine 357:1579-1588 . https://doi.org/10.1056/nejmoa071430

126. Duraipandian S, Traynor D, Kearney P, Martin C, O'Leary JJ, Lyng FM (2018) Raman spectroscopic detection of high-grade cervical cytology: Using morphologically normal appearing cells. Scientific Reports 8: . https://doi.org/10.1038/s41598-018-33417-8 